\title{
Site-specific climate analysis elucidates revegetation challenges for post-mining landscapes in eastern Australia
}

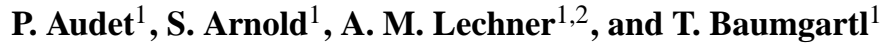 \\ ${ }^{1}$ Centre for Mined Land Rehabilitation, The University of Queensland, Brisbane, Australia \\ ${ }^{2}$ Centre for Environment, The University of Tasmania, Hobart, Australia
}

Correspondence to: P. Audet (p.audet@uq.edu.au) and S. Arnold (s.arnold@uq.edu.au)

Received: 11 December 2012 - Published in Biogeosciences Discuss.: 18 December 2012

Revised: 27 August 2013 - Accepted: 3 September 2013 - Published: 15 October 2013

\begin{abstract}
In eastern Australia, the availability of water is critical for the successful rehabilitation of post-mining landscapes and climatic characteristics of this diverse geographical region are closely defined by factors such as erratic rainfall and periods of drought and flooding. Despite this, specific metrics of climate patterning are seldom incorporated into the initial design of current post-mining land rehabilitation strategies. Our study proposes that a few common rainfall parameters can be combined and rated using arbitrary rainfall thresholds to characterise bioregional climate sensitivity relevant to the rehabilitation these landscapes. This approach included assessments of annual rainfall depth, average recurrence interval of prolonged low intensity rainfall, average recurrence intervals of short or prolonged high intensity events, median period without rain (or water-deficit) and standard deviation for this period in order to address climatic factors such as total water availability, seasonality and intensity - which were selected as potential proxies of both short- and long-term biological sensitivity to climate within the context of post-disturbance ecological development and recovery. Following our survey of available climate data, we derived site "climate sensitivity" indexes and compared the performance of 9 ongoing mine sites: Weipa, Mt. Isa and Cloncurry, Eromanga, Kidston, the Bowen Basin (Curragh), Tarong, North Stradbroke Island, and the Newnes Plateau. The sites were then ranked from most-to-least sensitive and compared with natural bioregional patterns of vegetation density using mean NDVI. It was determined that regular rainfall and relatively short periods of water-deficit were key characteristics of sites having less sensitivity to climate - as found among the relatively more temperate inland mining locations. Whereas, high rainfall variability, frequently
\end{abstract}

occurring high intensity events, and (or) prolonged seasonal drought were primary indicators of sites having greater sensitivity to climate - as found among the semi-arid centralinland sites. Overall, the manner in which these climatic factors are identified and ultimately addressed by land managers and rehabilitation practitioners could be a key determinant of achievable success at given locations at the planning stages of rehabilitation design.

\section{Introduction}

As elsewhere worldwide, rehabilitation of post-mining sites in the semi-arid and subtropical environments of eastern Australia have a general objective to establish specific types of native vegetation communities as defined in mine closure plans (DEHP, 2012; DRET, 2006; Bell, 2001; Bradshaw, 1997). Given the size and severity of mining disturbances, these environments often require extensive and costly rehabilitation of fundamental components of landscape complexity (Green and Sadedin, 2005). This typically involves the reconstruction of landform, lithology and soil toward the development of vegetation communities from early-establishment stages to long-term succession - which are all central themes to this special issue on "Ecosystems in transition" by Hüttl, Hinz, Kögel-Knabner, Schulin, Gerwin, and Subke (Eds.). In general, the in / ability to achieve an intended rehabilitation outcome is frequently attributed to the radical and potentially irreversible differences between the physico-chemical starting point of the post-disturbance environment compared to that of the intended post-rehabilitation outcome (Doley et al., 2012; Doley and Audet, 2013). Adding to these

Published by Copernicus Publications on behalf of the European Geosciences Union. 
circumstances, an emerging scenario suggests that global climatic factors should represent a further overarching challenge toward rehabilitation schemes, particularly in an era of climate change (Harris et al., 2006; Hobbs et al., 2009; Jones et al., 2012). Critical to and in many situations predominant for the success of post-mining land rehabilitation is the availability of water and hence the climatic characteristic of geographic regions. Echoing concerns by others (Hinz et al., 2006; Hodgkinson et al., 2010), climatic factors such as the regional seasonality and frequency of extreme rainfall and drought events represent inextricably interwoven components of landscape complexity which influence the development and survival of post-disturbance ecosystems at all stages of recovery. Still, specific metrics of site climate or seasonality are surprisingly seldom accounted for in mined land rehabilitation design. When climate factors are taken into consideration, the selected parameters (e.g., typically surrounding mean annual rainfall) tend to over-simplify any assessment of regional climatic obstacles. For these reasons, this analysis seeks to identify some of the climatic boundaries (i.e., primarily relating to rainfall) relevant to rehabilitation development and to determine the relative sensitivity of ongoing mine sites to climate across different geographic locations in eastern Australia. Overall, the manner in which these climatic factors are identified and ultimately addressed by land managers and rehabilitation practitioners could be a key determinant of achievable success at given locations at the planning stages of rehabilitation design.

The eastern Australian context for post-mining land rehabilitation provides a special backdrop for examining the effects of climate characteristics on the potential trajectories of post-disturbance landscapes (Tibbett et al., 2012), having many relevant parallels with other geographic locations (e.g., regions affected by monsoonal activity) in land disturbance and similar characteristic in the extent of seasonality and variability of climate. It holds an astonishing array of regional ecosystems - spread across equatorial, tropical and subtropical, desert, grassland, and temperate environments - with a diversity of flora and fauna deemed to be megadiverse and containing biodiversity hotspots of international significance (Williams et al., 2002; Myers et al., 2000). More significantly, it also holds vast mineral and metal resources and has an economic dependence on mining and mineral processing (particularly coal, iron ore, and bauxite) resulting in a range of anthropogenically disturbed landscapes. Unlike post-mining rehabilitation activities conducted in regions having rather stable and / or moderate seasonal variation (e.g., temperate North America and Europe), the rehabilitation of these affected landscapes can be significantly affected by erratic rainfall and sequential periods of drought and flooding which cause further challenges for rehabilitation schemes (e.g., dryland salinity, erosion and rapid degradation of soil fertility) (Williams et al., 2002). Following our survey of available climate data, this study presents climate sensitivity indexes (that are otherwise currently not available or accounted for in mine closure plans) comparing rainfall conditions found at 9 ongoing mine sites in which our research centre has been engaged in environmental monitoring. A central objective of this analysis is to emphasise notions of climate sensitivity as a rapid early-detection tool to better account for potential rehabilitation challenges among these ecosystems. Ultimately, we envisage that similar climate assessments could be tailored for other geographic locations with similar climatic conditions and undergoing equally severe disturbance impacts to optimize their rehabilitation outcomes.

\section{Materials and methods}

\subsection{Site selection and climate data}

Eastern Australian sites considered in our analyses - located at Weipa, Mt. Isa and Cloncurry (Ernest Henry), Eromanga, Kidston, Bowen Basin (Curragh), Tarong, North Stradbroke Island, and Newnes Plateau (Fig. 1) - were selected on the basis of being locations for extensive mining activities that are also under environmental monitoring by the Centre for Mined Land Rehabilitation (CMLR), providing us a fieldlevel familiarity with their respective climatic conditions and rehabilitation challenges. Each site (detailed in Table 1) had been significantly disturbed typically to the extent of affecting abiotic landform attributes and, under this pretext, had undergone or will soon undergo significant post-mining land rehabilitation aiming toward the re-establishment of selfsustaining natural vegetation communities. Together, these sites also provided an appropriate range of geo-climatic conditions (e.g., "dryness / wetness", rainfall periodicity, rainfall extremity / intensity) and sufficient data for examining broad-scale climate parameters across eastern Australia and comparing climate sensitivity criteria relevant to the recovery native ecosystems. A summary of the site-specific climatic zones and predominant vegetation classes for each site is shown (cf. Table 1) according to Williams et al. (2002) and the Interim Biogeographic Regionalisation for Australia classification system (IBRA (2012). Climate data were collected from and made available in the public domain by the Government of Australia's Bureau of Meteorology (Bureau of Meteorology, 2012d). As described in further detail below, the primary data parameters (Table 2) along with respective indication of ecological significance included: mean annual rainfall depth $\left(\mathrm{mm} \mathrm{yr}^{-1}\right)$, average recurrence intervals (years) of selected rainfall events based on Intensity-Frequency-Duration design rainfall charts (Bureau of Meteorology, 2013), and median period without rainfall (days) along with its standard deviation, as well as the length of the data capture. Data were collected from weather stations nearest to the given mine sites having the closest climatic similarity to these locations. 


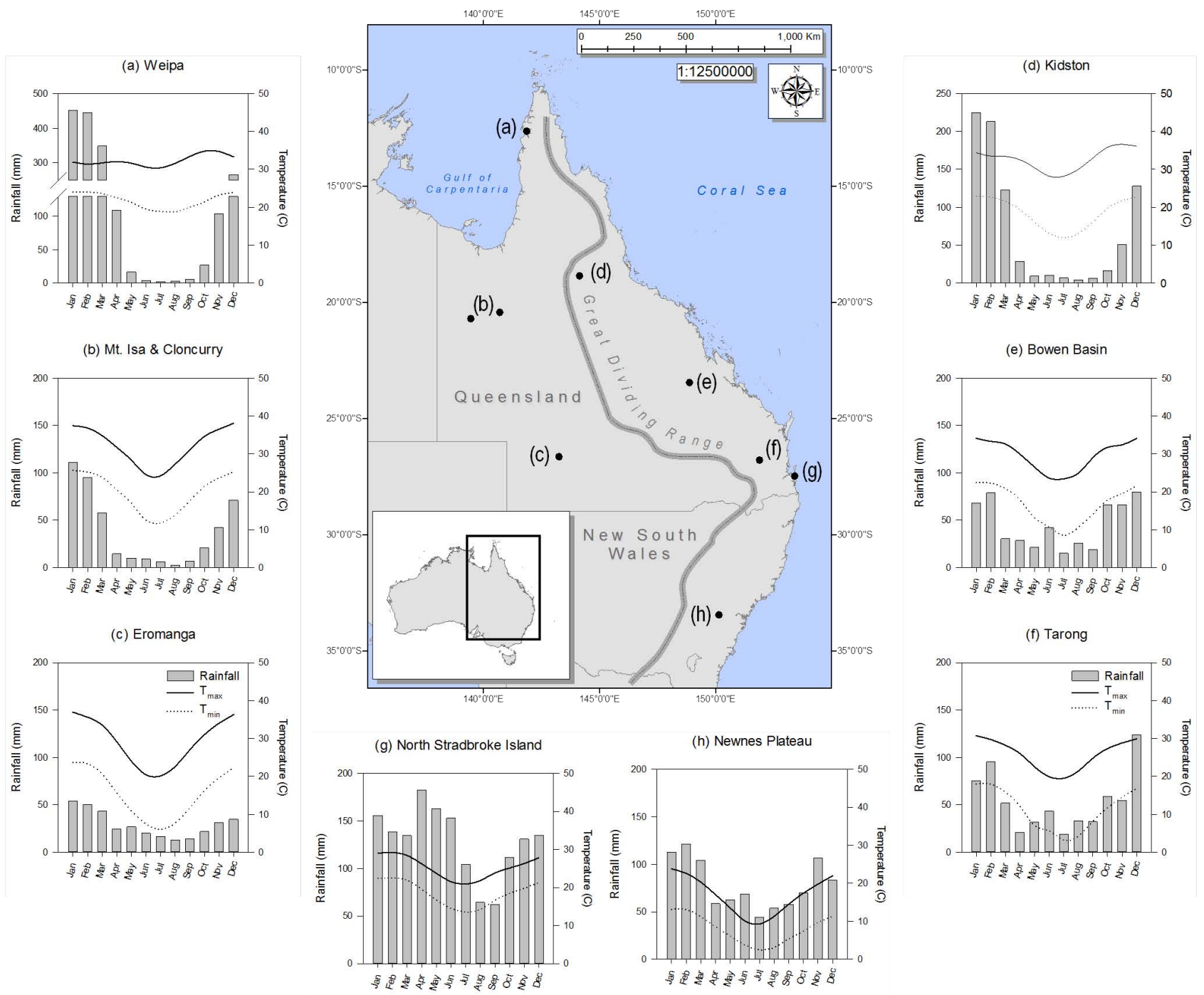

Fig. 1. Climate parameters (average monthly temperature and rainfall) for selected mine sites in eastern Australia.

\subsection{Rainfall metrics and analyses of specific climate patterns in Eastern Australia}

Site-specific values of long-term rainfall parameters and vegetation density are shown in Table 3 and form the core findings for all subsequent index analyses. From these data, each of the sites' climate parameters was rated qualitatively in relation to a series of rainfall criteria (cf. Table 2) which also included a description of the given parameter's intended indication of biological significance. Based on available data from (Bureau of Meteorology, 2012d) and (Bureau of Meteorology, 2013), annual rainfall depth $\left(R_{\mathrm{d}}\right)$ and average recurrence interval of prolonged events with low intensity rainfall $\left(\mathrm{ARI}_{\mathrm{rehab}}\right)$ were selected to be indicators of the sites' general level of water availability (i.e., total available water in the system). Meanwhile, the average recurrence intervals of short (ARI $\mathrm{Atorm}_{\text {sto }}$ ) and prolonged events with high intensity $\left(\mathrm{ARI}_{\text {cyclo }}\right)$ were selected as indicators of storm and cyclone events as proxies for associated problems of erosion or inundation. Likewise, the median period without rain (or waterdeficit) and standard deviation for this period were indicators of water limitation and its inherent seasonal variability (i.e., the degree to which rainfall events were either regular or erratic).

\subsection{Determination of data thresholds}

Data thresholds were determined by calculating the sensitivity of certain climatic patterns leading to success or failure of revegetation attempts. The results were rated as either (a) less sensitive (ideal), (b) moderately sensitive (adequate), or (c) highly sensitive (potentially problematic) and all 6 of the climate parameters in Table 3 were categorised for all of our analyses. Therefore, the criteria and range values for rating the data (Table 2) were selected according to a thorough review of the literature and expert opinions based on available 
Table 1. Biogeographic characteristics for each post-mining site.

\begin{tabular}{|c|c|c|c|c|}
\hline Climate $^{\mathrm{a}}$ & Major Vegetation Type ${ }^{b}$ & Site Name & Location & $\begin{array}{l}\text { Primary } \\
\text { Commodity }\end{array}$ \\
\hline $\begin{array}{l}\text { Desert/ } \\
\text { Semi-Arid Interior }\end{array}$ & Scrub and Heathland & Eromanga & $\begin{array}{l}26^{\circ} 40^{\prime} 11 \mathrm{~S} \\
143^{\circ} 16^{\prime} 11 \mathrm{E}\end{array}$ & Oil and Gas \\
\hline Temperate Highlands & $\begin{array}{l}\text { Shrubland and } \\
\text { Swamps }\end{array}$ & Newnes Plateau & $\begin{array}{l}33^{\circ} 28^{\prime} 23 \mathrm{~S} \\
150^{\circ} 9^{\prime} 33 \mathrm{E}\end{array}$ & Coal \\
\hline $\begin{array}{l}\text { Wet Subtropical } \\
\text { Coast }\end{array}$ & $\begin{array}{l}\text { Open-forest and } \\
\text { Woodland }\end{array}$ & $\begin{array}{l}\text { N. Stradbroke } \\
\text { Island }\end{array}$ & $\begin{array}{l}27^{\circ} 30^{\prime} 00 \mathrm{~S} \\
153^{\circ} 25^{\prime} 00 \mathrm{E}\end{array}$ & Mineral Sands \\
\hline \multirow[t]{2}{*}{$\begin{array}{l}\text { North-east Wet/ } \\
\text { Dry Tropics }\end{array}$} & \multirow[t]{2}{*}{$\begin{array}{l}\text { Tropical Shrubland } \\
\text { and Savannah }\end{array}$} & Weipa & $\begin{array}{l}12^{\circ} 37^{\prime} 44^{\prime \prime} \mathrm{S} \\
141^{\circ} 52^{\prime} 44^{\prime \prime} \mathrm{E}\end{array}$ & Bauxite \\
\hline & & Kidston & $\begin{array}{l}18^{\circ} 52^{\prime} 46^{\prime \prime} \mathrm{S} \\
144^{\circ} 9^{\prime} 12^{\prime \prime} \mathrm{E}\end{array}$ & Gold \\
\hline \multirow[t]{3}{*}{$\begin{array}{l}\text { Semi-Arid Tropical/ } \\
\text { Subtropical Plains }\end{array}$} & \multirow[t]{3}{*}{$\begin{array}{l}\text { Semi-Arid Woodland } \\
\text { and Savannah Grassland }\end{array}$} & Mt. Isa & $\begin{array}{l}20^{\circ} 44^{\prime} \mathrm{S} \\
139^{\circ} 30^{\prime} \mathrm{E}\end{array}$ & $\begin{array}{l}\text { Lead, Silver, } \\
\text { Copper, Zinc }\end{array}$ \\
\hline & & Cloncury & $20^{\circ} 26^{\prime} 20 \mathrm{~S}$ & Copper, Gold, \\
\hline & & Ernest Henry Mine & $140^{\circ} 42^{\prime} 47 \mathrm{E}$ & Iron Ore \\
\hline \multirow[t]{2}{*}{$\begin{array}{l}\text { Subtropical Slopes/ } \\
\text { Plains }\end{array}$} & \multirow[t]{2}{*}{ Humid Woodland } & $\begin{array}{l}\text { Bowen Basin } \\
\text { (Curragh) }\end{array}$ & $\begin{array}{l}23^{\circ} 28^{\prime} 15 \mathrm{~S} \\
148^{\circ} 53^{\prime} 15 \mathrm{E}\end{array}$ & Coal \\
\hline & & Tarong & $\begin{array}{l}26^{\circ} 48^{\prime} 34 \mathrm{~S} \\
151^{\circ} 54^{\prime} 13 \mathrm{E}\end{array}$ & Coal \\
\hline
\end{tabular}

\footnotetext{
a (Hutchinson et al., 2005; Williams et al., 2002).
}

b (IBRA 7, 2012)

agricultural and environmental management assessments to provide arbitrary classification thresholds (or data cut-off values) relevant to both short- and long-term vegetation development (DERM (2010) and Fraser et al. (2010)). For example, according to Pessarakli's (2001) guidelines for plant and crop stress (among others), it was generally assumed that very low $R_{\mathrm{d}}$ values as well as very high values of median period without rain $\left(R_{0}\right)$, standard deviation of period without rain $S_{\mathrm{R} 0}$ and $\mathrm{ARI}_{\text {rehab (i.e., infrequent recurrence) }}$ generally impose sub-optimal plant growth conditions due to the risk of water deficit. That being said, the contrary (i.e., frequent recurrence of storm and cyclone events (very low values of $\mathrm{ARI}_{\text {storm }}$ and $\mathrm{ARI}_{\text {cyclo }}$ )) would also result in suboptimal conditions due to the risk of inundation / water logging or soil erosion. Within the context of post-mining land rehabilitation, any such sub-optimal growth conditions was presumed to be detrimental to landscape revegetation leading to our classification of sites being deemed either more or less sensitive to climate. Although specific site parameters and landform characteristics are known to result in some finerscale variation, the classification thresholds applied here still provided a general depiction of site sensitivity to weather which currently is not accounted for in land rehabilitation assessments.

\subsection{Designation of un / favourable criteria and aggregation of indexes}

A quantitative sensitivity index (SI) depicting the frequency of favourable (S) and unfavourable (SP) rainfall conditions was calculated from the site-specific climate ratings assessed based on criteria in Table 2 and data parameters in Table 3 . More specifically, the total number of favourable rainfall characteristics were calculated based on the sum of both the less sensitive $\left(S_{\mathrm{i}}\right)$ and moderately sensitive $\left(S_{\mathrm{m}}\right)$ ratings. Meanwhile, the total number of unfavourable characteristics were calculated based on the sum of highly sensitive criteria for each site (SP). SI values were then combined to determine a linear aggregated index defined by calculating the difference between the favourable criteria $\left(S_{\mathrm{i}}+S_{\mathrm{m}}\right)$ and the potentially problematic and highly sensitive criteria (SP):

$\mathrm{SI}_{1}=\mathrm{S}_{\mathrm{i}}+\mathrm{S}_{\mathrm{m}}-\mathrm{SP}$ 
Table 2. Rainfall parameters for climate sensitivity criteria and their biological or morphologic significance.

\begin{tabular}{|c|c|c|c|c|}
\hline \multicolumn{5}{|c|}{ Sensitivity criteria ${ }^{(a, b, c)}$} \\
\hline Measure & $\begin{array}{l}\text { Less Sensitive } \\
\quad \text { (Ideal) }\end{array}$ & $\begin{array}{l}\text { Moderately Sensitive } \\
\text { (Adequate) }\end{array}$ & $\begin{array}{c}\text { Highly Sensitive } \\
\text { (Potentially Problematic) }\end{array}$ & Indication of ... \\
\hline $\mathrm{R}_{\mathbf{d}}\left(\mathrm{mm} \mathrm{yr}^{-1}\right)$ & $>1000$ & $1000-500$ & $<500$ & $\begin{array}{l}\text { Level of water availability } \\
\text { (co-classifier biogeographic regionalisation) }\end{array}$ \\
\hline $\mathrm{ARI}_{\text {cyclo }}$ (years) & $>100$ & $20-100$ & $<20$ & $\begin{array}{l}\text { Frequency of intense cyclone events } \\
\text { (sensitivity to erosion \& inundation) }\end{array}$ \\
\hline $\mathrm{ARI}_{\text {storm }}$ (years) & $>100$ & $20-100$ & $<20$ & $\begin{array}{l}\text { Frequency of intense storm events } \\
\text { (sensitivity to erosion) }\end{array}$ \\
\hline $\mathrm{ARI}_{\text {rehab }}$ (years) & $<1$ & $1-2$ & $>2$ & Water availability \\
\hline $\mathrm{R}_{\mathbf{0}}$ (days) & $<5$ & $5-10$ & $>10$ & $\begin{array}{l}\text { Duration of water deficit } \\
\text { (water limitation) }\end{array}$ \\
\hline SRo (days) & $<10$ & $10-20$ & $>20$ & $\begin{array}{l}\text { Ir/regularity of water deficit } \\
\text { (intensity of water limitation) }\end{array}$ \\
\hline
\end{tabular}

$R_{\mathrm{d}}$ : annual rainfall depth.

ARI $\mathrm{rehab}_{\text {: }}$ average recurrence interval of rainfall event with intensity of $2 \mathrm{~mm} \mathrm{r}^{-1}$ and duration of $48 \mathrm{hr}$.

ARI $_{\text {storm: }}$ average recurrence interval of rainfall event with intensity of $100 \mathrm{~mm} \mathrm{hr}^{-1}$ and duration of $30 \mathrm{~min}$.

$\mathrm{ARI}_{\text {cyclo: }}$ : average recurrence interval of rainfall event with intensity of $10 \mathrm{~mm} \mathrm{hr}^{-1}$ and duration of $24 \mathrm{hr}$.

$R_{0}$ : median period with no rainfall.

$s_{\mathrm{R} 0}$ : standard deviation of period with no rainfall.

a (DERM, 2010)

b (Fraser et al., 2010)

c (IBRA 7, 2012)

Different aggregate weightings (e.g., emphasising less sensitive $\left(2 S_{\mathrm{h}}\right)$ or highly sensitive (2 SP) or both) were then applied to determine whether the ranking of site sensitivity to climate would change when certain parameters were over / under-emphasised:

$\mathrm{SI}_{2}=2 \mathrm{~S}_{\mathrm{i}}+\mathrm{S}_{\mathrm{m}}-\mathrm{SP}$,

$\mathrm{SI}_{3}=\mathrm{S}_{\mathrm{i}}+\mathrm{S}_{\mathrm{m}}-2 \mathrm{SP}$,

$\mathrm{SI}_{4}=2 \mathrm{~S}_{\mathrm{i}}+\mathrm{S}_{\mathrm{m}}-2 \mathrm{SP}$.

While it was anticipated that site sensitivity to climate should align with general biogeographic parameters (e.g., coastal vs. inland sites), the application of different aggregate weightings (as above) was applied to further discriminate between more subtle climate variations. Ultimately, these data were plotted in ascending / descending order of the site index values which closely corresponded to the same order across all analyses.

\subsection{Estimates of vegetation density (via remote sensing) and data analysis}

The relationship between the ecological sensitivity to climatic factors and natural biogeographic regionalisation veg- etation patterns was assessed using the remotely sensed normalised difference vegetation index (NDVI). This is commonly used as a spatial estimate of vegetation density and provides an arbitrary determinant of biozones and seasonal change (e.g., arid zones $=$ low biomass and vegetation density; temperate zones $=$ high biomass and vegetation density). Average NDVI values for two selected time periods (referring distinct periods of el Niño and la Niña climate extremes; see Appendix A for details) and their associated coefficients of variation (NDVI-CV) were derived from the Global Inventory Modelling and Mapping Studies (GIMMS) dataset (Pinzon et al., 2005; Tucker et al., 2005). As described in Appendix 1, the two events were chosen to represent the most recent of the 12 strongest el Niño and la Niña events identified in an analysis by Bureau of Meteorology (Bureau of Meteorology, 2012e, c) within the period where GIMMS data is available (Table A1) to capture the annual trends in weather such as wet and dry season. Site specific NDVI were then plotted against all of the aggregated sensitivity indexes as well as the mean annual rainfall, median period without rain and standard deviation of the period without rain (described above) to determine the strength of correlation between each parameter; but not the average recurrence intervals since these are not continuous values. This was done to determine the most significant climatic / rainfall predictors of bioregional vegetation density, and which of the criteria were most well correlated with long-term / broad-scale 


\section{Climate Sensitivity Indexes}
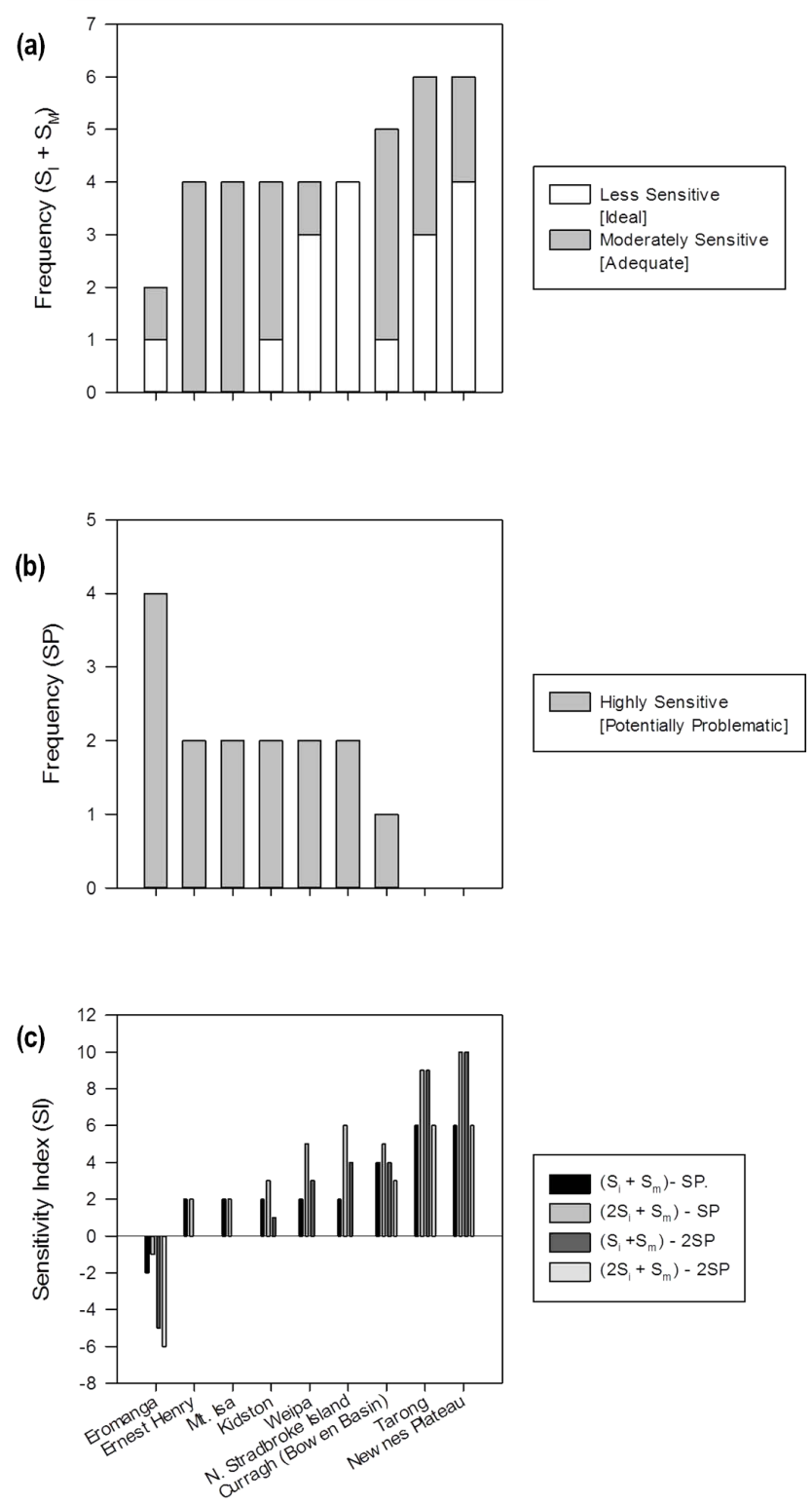

Fig. 2. Frequency of (a) favourable criteria (both ideal $\left(S_{\mathrm{i}}\right)+$ moderately sensitivity $\left(S_{\mathrm{m}}\right)$ ) and (b) unfavourable potentially problematic (SP) that eventually build (c) the aggregated sensitivity indexes. Threshold values used to determine these sensitivity criteria are shown in Table 2.

vegetation activity. All of the Spearman non-parametric correlation coefficients $(r)$, degrees of freedom (df), and $p$ value estimates were calculated using SigmaPlot for Windows v. 12.0 (Systat Software Inc., San Jose, USA).

\section{Results}

A summary of all site-specific rainfall metrics for selected mine sites across eastern Australia is shown (Table 3). Values deemed to be less sensitive or highly sensitive (i.e., (ideal) vs. (potentially problematic)) according to the given climate sensitivity criteria (as defined in Table 2) are highlighted. On their own, there were no clearly defined data trends regarding the incidence of less sensitive vs. moderately sensitive criteria among the sites (Fig. 2a). Yet, when combined, the final sensitivity index incorporating both (ideal) and (adequate) values indicated a pattern whereby the relatively more temperate central-coastal sites (such as Newnes Plateau, Tarong, Bowen Basin (Curragh), and N. Stradbroke Island) had more favourable rainfall conditions than the central-inland sites. Conversely, the highly sensitive index (Fig. 2b) showed the opposite trend whereby Eromanga had the most potentially problematic characteristics, though other arid central-inland sites (Mt. Isa and Cloncurry (Ernest Henry)) had no ideal rainfall characteristics (Fig. 2a). Interestingly, upon closer analysis of Table 3, it is apparent that sites deemed ideal in relation to climate sensitivity analyses were not primarily linked to the regularity of water availability (i.e., high values of $R_{\mathrm{d}}$ and / or low values of $\mathrm{ARI} \mathrm{I}_{\text {rehab }}$ ). For example, for the less sensitive sites values of $R_{\mathrm{d}}$ ranged from $578.1 \mathrm{~mm} \mathrm{yr}^{-1}$ in the Bowen Basin (Curragh) to $786.9 \mathrm{~mm} \mathrm{yr}^{-1}$ in Newnes Plateau; values that are much lower compared to the coastal site at $\mathrm{N}$. Stradbroke Island $\left(R_{\mathrm{d}}=1603.8 \mathrm{~mm} \mathrm{yr}^{-1}\right)$ and the tropical location in Weipa $\left(R_{\mathrm{d}}=1787 \mathrm{~mm} \mathrm{yr}^{-1}\right)$. On the other hand, sites deemed potentially problematic were linked to their propensity for drought and irregularity / seasonality of rainfall (e.g., $R_{\mathrm{d}}<500 \mathrm{~mm} \mathrm{yr}^{-1}$, and $R_{0}>6$ days or $S_{\mathrm{R} 0}$ $>20$ days).

That being said, Kidston and Weipa - which are located among the northeast wet / dry tropics and showed adequate annual / daily water availability - were consistently found to be intermediately sensitive due to their prominently seasonal wet / dry rainfall distribution. From these findings, the aggregated indexes based on the combination of all index values (Fig. 2c) then provided a unifying value for these trends and various positive / negative weightings of (ideal) vs. (potentially problematic) values further emphasised the most / least favourable climate conditions among each site. Overall, the ranking of sites for all aggregated values from mostto-least sensitive (or from most-to-least problematic) was: Eromanga $<$ Cloncurry (Ernest Henry) and Mt. Isa $<$ Kidston and Weipa and N. Stradbroke Island $<$ Bowen Basin (Curragh) and Tarong and Newnes Plateau. Despite each site having very different values of annual rainfall depth, this order of sites also appeared to coincide with the general pattern of monthly rainfall seasonality (Fig. 1a-h). In this regard, Newnes Plateau, Tarong, Bowen Basin (Curragh), and N. Stradbroke Island indicated more consistent rainfall availability across all months of the year, meanwhile Kidston, Weipa, Mt. Isa and Cloncurry (Ernest Henry) indicated 

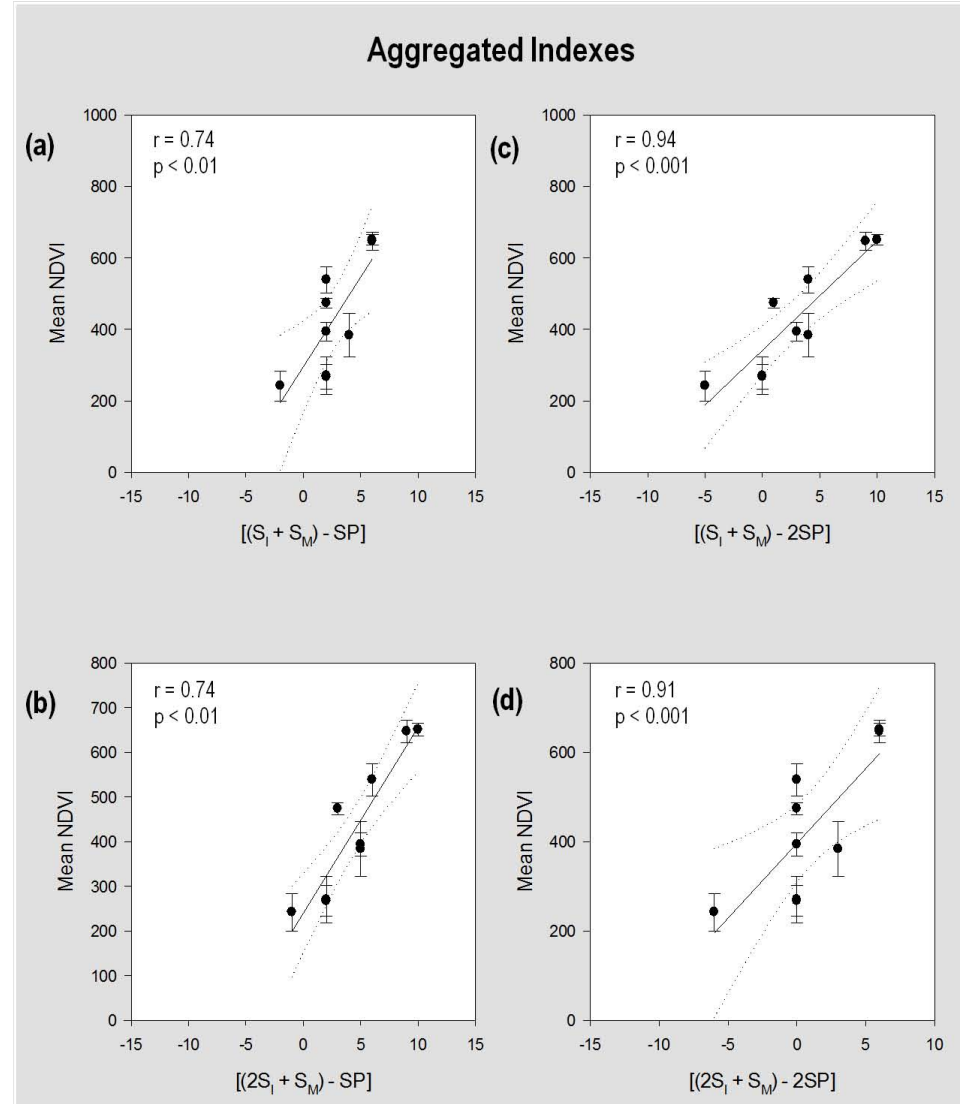
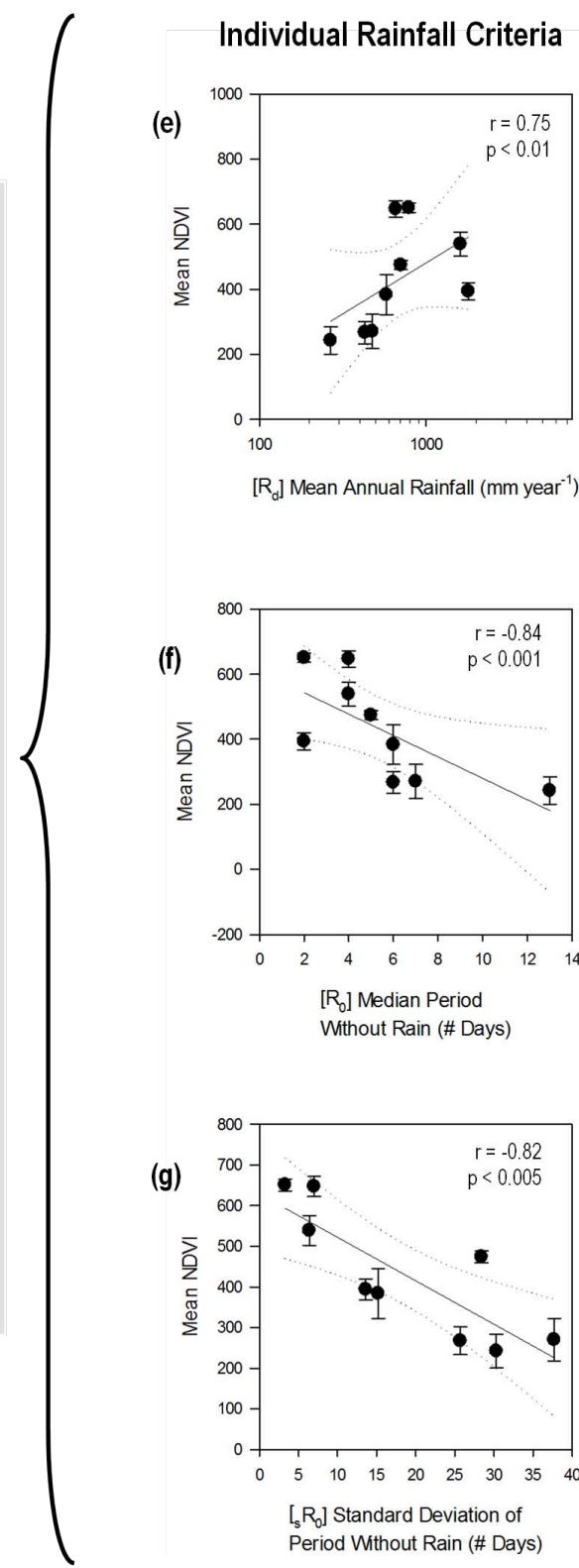

$\left[R_{d}\right]$ Mean Annual Rainfall $\left(m m\right.$ year $\left.{ }^{-1}\right)$
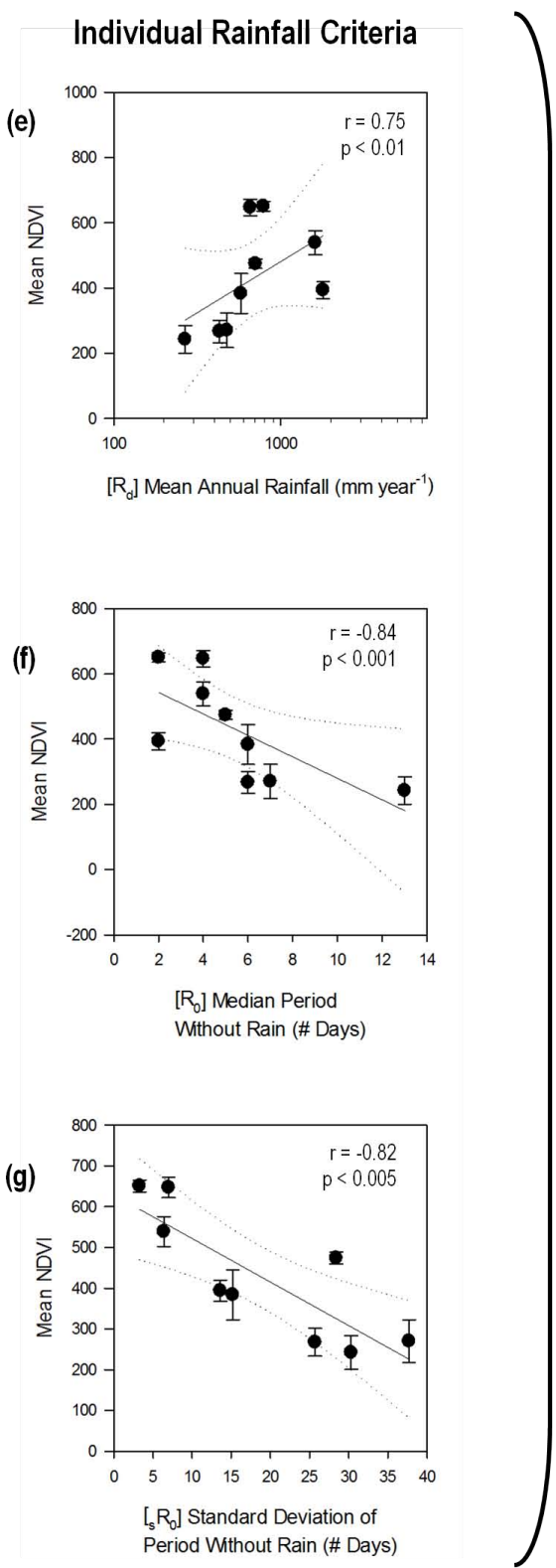

Fig. 3. Mean NDVI in relation to aggregated sensitivity indexes (shaded, a-d) and individual rainfall parameters (précis, e-g). Refer to Fig. A1 for spatial distribution of NDVI across eastern Australia.

distinct periods of drought / water-deficit. Eromanga indicated no apparent rainfall seasonality, but had the lowest total rainfall among all locations.

The relationship between the ecological sensitivity to climatic factors and "natural" or biogeographic regionalisation vegetation patterns was assessed using the remotely sensed "normalised difference vegetation index" (NDVI). Spatial distribution patterns are shown in Appendix 1 whereby NDVI values generally corresponded with the desert / semiarid interior zones (including Eromanga, Mt. Isa and Cloncurry (Ernest Henry)) having lower total vegetation density vs. the temperate / wet subtropical coast and highlands
(Tarong, Newnes Plateau, N. Stradbroke Island and Bowen Basin (Curragh)) and northeast wet / dry tropics (Weipa and Kidston) which indicated higher total vegetation density. From these spatial distribution data, mean NDVI values were plotted in relation to each of the aggregated sensitivity indexes (App. 1) described above. Significant positive correlations were found for all weighted indexes according to Spearman's Rank test (Fig. 3a: $r=0.74, p<0.01$; Fig. 3b: $r=0.74, p<0.014$; Fig. 3c: $r=0.94, p<0.001$; Fig. 3d: $r=0.91, p<0.001)$. When plotted in relation to the variation of NDVI (CV-NDVI), the aggregated sensitivity indexes showed no such correlations (data not shown) suggesting 
that these indexes were stable / constant in relation to seasonal changes - i.e., even in regions of high rainfall seasonality, variation in rainfall did not result in significant annual changes in NDVI.

Lastly, the individual rainfall parameters used throughout all of the analyses are also plotted in relation to mean NDVI to determine the climate metrics most strongly correlated with natural vegetation patterns (Fig. $3 \mathrm{e}-\mathrm{g}$, précis). Here, only the mean annual rainfall depth $\left(R_{\mathrm{d}}\right)$ showed a significant positive correlation (Fig. 3e: $r=0.75, p<0.01$ ), whereas correlations with the median period without rain $\left(R_{0}\right)$ (Fig. 3f: $\left.r=-0.84, p<0.001\right)$ and standard deviation of period without rain $\left(S_{R 0}\right)$ (Fig. $3 \mathrm{~g}: r=-0.82, p<0.005$ ) were significantly negative. This outcome suggests that these three parameters were most closely related to the broad-scale natural / native vegetation density and total biomass across each bioregion.

\section{Discussion}

Our study demonstrates that a few common rainfall parameters can be combined and classified using arbitrary rainfall thresholds to characterise bioregional climate sensitivity patterns relevant to the rehabilitation of highly disturbed landscapes. Given the role that climate should hold in the revegetation of rehabilitated and recovering environments worldwide (Harris et al., 2006; Hobbs et al., 2009; Jones et al., 2012), such readily computed metrics can contribute a beneficial first-step toward hypothesising climate boundaries of the post-disturbance environment and the likelihood of sub / optimal conditions for plant growth and revegetation at broad-scale. Although these criteria (or similar) are seldom if at all taken into consideration among many post-mining planning strategies, a notable advantage of this approach was that selected rainfall parameters could be chosen to represent multiple indicators of both short- and long-term biological and morphologic sensitivity to climate, especially regarding ecological development and recovery. For example, mean annual rainfall (applied as a gross metric of water availability) is often used as a typical co-classifier of biogeographic regionalisation. Yet, it alone cannot account for the propensity and / or sensitivity of sites for erosion, non-disruptive water supply, water limitation or most of all the regularity and seasonality of these parameters. Therefore, in our study, alternative parameters were selected to more effectively determine the seasonality, regularity, and intensity of weather, such as the frequency of various rainfall events (e.g., low vs. high intensity rainfall events) combined with both median and standard deviation of periods with no rain (i.e., length and variation of drought). Overall, these parameters provided a more complete picture of site sensitivity and the potential challenges arising as a result. That being said, by first rating and combining these parameters and then ranking the sites using aggregated metrics of sensitivity from most-to- least sensitive, we then determined that the basic distribution of site sensitivities to climate coincided closely with existing bioregional classification boundaries. As supported by natural vegetation patterns estimated using the mean NDVI, the relatively more temperate coastal sites indicated lesser sensitivity than arid central-inland sites (Hutchinson et al., 2005; IBRA 7, 2012; Williams et al., 2002). This is an indication that the outcomes of our climate rankings (which were based on finer-scaled parameters) still aligned with existing broadscale patterns and processes. The importance of these outcomes could appear somewhat trivial for land planners and rehabilitation practitioners assessing potential boundaries to rehabilitation in locations where climate patterns are more predictable (i.e., less erratic) and / or express very little variation within growing seasons, namely temperate regions in North America and Europe. However, in eastern Australia as well as other locations with comparable climatic variability, these factors could contribute in identifying the sometimes narrow window of challenge and opportunity which determine the range of achievable outcomes in certain environments (Hinz et al., 2006; Hodgkinson et al., 2010). For this reason, we consider that the general approach could be applied as a preliminary site assessment for identifying some of the broad-scale climate boundaries affecting revegetation schemes. Since general public expectations are that mining proponents rehabilitate affected lands fairly soon after disturbance (Burton et al., 2012), even under less than optimal conditions, it is necessary to identify as soon as possible after the event of disturbance both subtle and obvious factors that could favour or hinder the early-establishment of plants (e.g., frequency of various rainfall events, and duration and variation of periods of water-deficit). As discussed below in further detail, the formulation of any such preliminary assessments could represent a necessary hypothesis-building component in support of future investigations or optimisation strategies seeking to address finer-scaled effects associated with unfavourable climate conditions, such as erosion control, management of soil fertility and matrix structure, maintenance of seed / ling viability and survivorship, etc.

\subsection{What criteria cause sites to be more or less sensitive?}

At their extremes, the manner in which the post-mining sites were deemed most-to-least sensitive across eastern Australia has provided a rather predictable depiction of how broadscale rainfall patterns shape climate boundaries among arid central-inland vs. temperate coastal-hinterland locations. Evidently, regular rainfall and relatively short periods of waterdeficit are common characteristics of favourable climate conditions, whereas prolonged seasonal drought with high variation and frequently occurring intense rainfall events (storm or cyclone events) are primary characteristics of site sensitivity. The integration of alternative indicators of seasonality and intensity has provided further criteria to discriminate 
Table 3. Site-specific values of long-term rainfall parameters.

\begin{tabular}{|c|c|c|c|c|c|c|c|}
\hline Site Name & $T_{\text {obs }}$ (years) & $R_{\mathrm{d}}\left(\mathrm{mm} \mathrm{yr}^{-1}\right)$ & ARI $_{\text {cyclo }}$ (years) & $\mathrm{ARI}_{\text {storm }}$ (years) & ARI $_{\text {rehab }}$ (years) & $R_{0}$ (days) & $\mathrm{s}_{R o}$ (days) \\
\hline Cloncurry (Ernest Henry) & 44 & 476.1 & $50-100$ & $20-50$ & $1-2$ & 7 & 37.7 \\
\hline Kidston & 87 & 704.7 & $50-100$ & $10-20$ & $<1$ & 5 & 28.4 \\
\hline Mt. Isa & 79 & 429.3 & $50-100$ & $20-50$ & $1-2$ & 6 & 25.7 \\
\hline Newnes Plateau & 134 & 786.9 & $>100$ & $>100$ & $1-2$ & 2 & 3.3 \\
\hline Weipa & 95 & 1787.0 & $10-20$ & $1-2$ & $<1$ & 2 & 13.6 \\
\hline
\end{tabular}

Values deemed to be "less sensitive" (ideal) and "highly sensitive" (potentially problematic) are highlighted based on the climate sensitivity criteria (Table 2).

$T_{\mathrm{obs}}$ : length of dataset.

$R_{\mathrm{d}}$ : annual rainfall depth.

$\mathrm{ARI}_{\text {rehab }}$ : average recurrence interval of rainfall event with intensity of $2 \mathrm{~mm} \mathrm{hr}^{-1}$ and duration of $48 \mathrm{hr}$.

ARI storm: average recurrence interval of rainfall event with intensity of $100 \mathrm{~mm} \mathrm{hr}^{-1}$ and duration of $30 \mathrm{~min}$.

$\mathrm{ARI}_{\text {cyclo }}$ : average recurrence interval of rainfall event with intensity of $10 \mathrm{~mm} \mathrm{hr}^{-1}$ and duration of $24 \mathrm{hr}$.

$R_{0}$ : median period of consecutive days with no rainfall.

$s_{\mathrm{R} 0}$ : standard deviation of period of consecutive days with no rainfall.

site sensitivity to climate that can be used to differentiate the sensitivity of regionally related sites, such as: Mt. Isa and Ernest Henry vs. Eromanga; or, Kidston vs. Weipa vs. N. Stradbroke Island. These fundamental relationships can be illustrated conceptually in our climate sensitivity matrix (Fig. 4) which identifies a range of climate scenarios (including moderately sensitive outcomes) in relation to the combined effects of differential rainfall availability and seasonal variation. Within the context of mine site rehabilitation, the range of un / favourable climatic conditions found among these sites should undoubtedly define (and perhaps even exacerbate) the challenges of revegetating reconstructed landscapes, particularly at the stages of plant early-establishment. That being said, our onsite experience (albeit anecdotal due to differences in site-specific metrics used between each project) tends to support these more vs. less climate sensitive site scenarios through ongoing environmental monitoring of the post-mining sites ${ }^{1}$. In regards to sites deemed most favourable (or less climate sensitive) such as the Newnes Plateau, Tarong, the Bowen Basin (Curragh), and N. Stradbroke Island (Audet et al., 2013; Gravina et al., 2012; Gravina et al., 2011; McKenna and Baiquni, 2011), rehabilitation development has achieved sufficient levels of vegetation structure and (morphologic) stability over a seemingly short period of time (approx. 10-15 years post-rehabilitation). In terms of biological significance, rainfall patterns in favour of relatively lower seasonal variation and fewer large vs. small intensity events have corresponded to conditions conducive to the stabilisation of the growth substrate and earlyestablishment of plants. Under these relatively more temperate environmental conditions, climate does not appear to represent a significant abiotic threshold or boundary for ecolog-

\footnotetext{
${ }^{1}$ Monitoring of the Newnes Plateau is still in its early stages, therefore long-term data collection was insufficient to assess ecological development at present time.
}

ical development. By contrast, rehabilitation development of arid central-inland sites deemed most climate sensitive and therefore potentially problematic, such as Eromanga, Mt. Isa and Cloncurry (Ernest Henry), has indicated lower rates of vegetation establishment - even for native species that are well adapted to drought - and a propensity for seasonal flooding (Gravina and Grigg, 2004; Vickers et al., 2012). Here, the combination of seasonal periods without rainfall followed by frequently occurring high intensity rainfall events has contributed to a high risk of impacting success in plant establishment during periods with and without rain. Periods of high amount and intensity rainfall may lead to elevated runoff increasing the sensitivity to erosion and loss / leaching of topsoil fertility, and thereby representing a substantial abiotic impediment to vegetation establishment. Similar patterns of site sensitivity to climate are also found for intermediately classified locations, such as tropical Weipa and Kidston, which indicated adequate water availability yet highly pronounced seasonal rainfall (Fig. 1a, d). In this case, intensive soil stabilisation, drainage and irrigation were required to achieve adequate revegetation levels (Bao et al., 2012; Gravina and Grigg, 2007). And so, even in cases where annual rainfall appears to be adequate (e.g., Weipa or N. Stradbroke Island), the seasonal intensity of rainfall patterns can have severe consequences for rehabilitation development over the short term.

\section{Conclusions and considerations for rehabilitation}

A main consideration of our analysis is that the regional intensity, seasonality, and extremity of rainfall should represent a primary determinant of rehabilitation success among post-disturbance landscapes. In this regard, the rehabilitation of mine sites is expensive, and so strategies that can optimise implementation of rehabilitation in locations having 


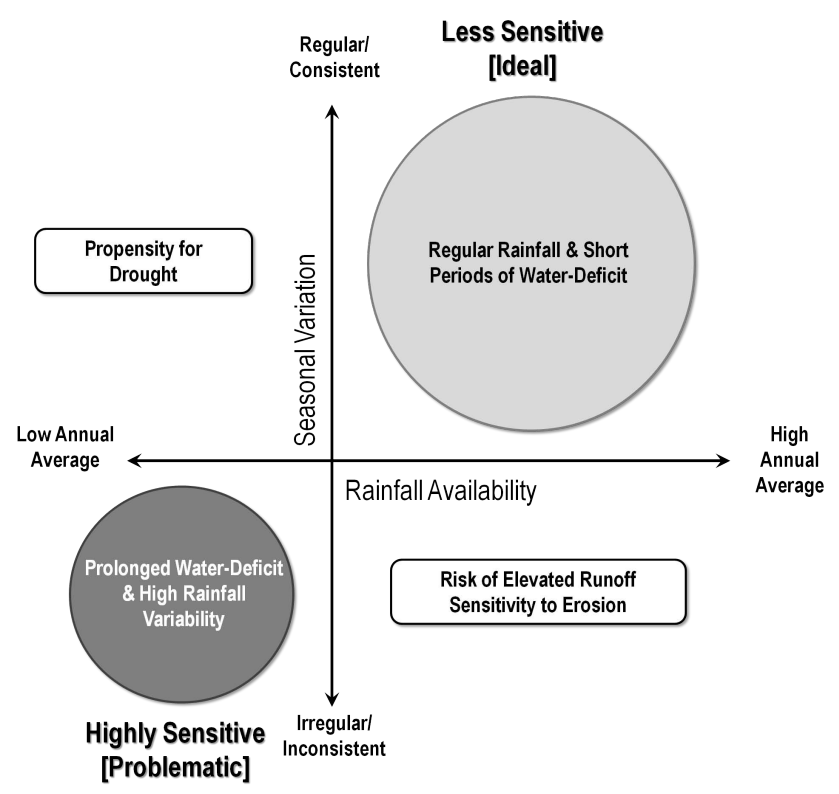

Fig. 4. Conceptual matrix of site-specific sensitivity to climatic factors in the context of rehabilitation development.

sub-optimal environmental conditions would have direct impact on current operations (Burton et al., 2012). Based on the common rainfall criteria used here, the strategy of identifying a given site's characteristic regarding rainfall availability and temporal distribution could be readily applied to other locations which are similarly affected by climate / rainfall extremes and used to guide initial rehabilitation planning while adding no significant additional time or costs to rehabilitation design. It is our view that rehabilitation expectations and the amount of investment required for rehabilitation of sites within different climatic zones should, in part, be driven by an understanding of potential climate boundaries - even in temperate locations and not necessarily limited simply to rainfall depth. Since these components are generally lacking from most planning assessments, we believe that approaches such as those presented here should represent a necessary starting point for further experimental investigations, which could then feedback and improve upon current monitoring activities, including bioregional climate and vegetation modelling. Although it would be imprudent to make site-specific recommendations concerning landmanagement strategies based only on such broad-scale classifications, the determination of climate sensitivity should still provide value-added for hypothesizing potential abiotic boundaries affecting ecological development and a generalised prognosis for rehabilitation development. For example, in cases of high site sensitivity to climate, rehabilitation planning could identify a need for extended commitments to rehabilitation through intensive monitoring of ecological performance in relation to seasonal climate patterns and (when required) progressive land management to optimise the per-
Table A1. Average values of SOI (Southern Oscillation Index) for twelve La Niña and El Niño events, respectively

\begin{tabular}{cccc}
\hline \multicolumn{2}{c}{ La Niña events } & \multicolumn{2}{c}{ El Niño events } \\
Year & Average SOI & Year & Average SOI \\
\hline 1910 & 16.3 & $1905 / 06$ & -8.0 \\
1916 & 11.9 & $1914 / 15$ & -8.4 \\
1917 & 25.0 & $1940 / 41$ & -18.2 \\
1938 & 11.9 & $1941 / 42$ & -8.4 \\
1950 & 16.1 & $1965 / 66$ & -4.8 \\
1955 & 15.8 & $1972 / 73$ & -9.5 \\
1956 & 9.4 & $1977 / 78$ & -12.7 \\
1971 & 10.0 & $1982 / 83$ & -28.4 \\
1973 & 14.3 & $1987 / 88$ & -3.5 \\
1974 & 6.8 & $1991 / 92$ & -17.1 \\
1975 & 18.6 & $1994 / 95$ & -6.1 \\
1988 & 13.0 & $1997 / 98$ & -17.3 \\
\hline
\end{tabular}

formance of rehabilitation in relation to these conditions. This could include pre-emptive mitigation strategies applied to overcome abiotic barriers of site sensitivity such as soilcover designs that trigger water availability. For instance, deep soils and low compaction to increase water holding capacity; or, silty / clayey soils to increase plant available water. Likewise, landform designs can be applied that minimise the effects of highly impactful rainfall events. For instance, gentle slopes that minimise runoff, facilitate infiltration, and minimise erosion; or, aspect design that minimises evapotranspiration. By extension, these rather simple and precautionary design considerations could hold significant implications, for example, when attempting to maintain seed viability during unfavourable climate conditions and later reducing ecophysiological stress / strain on seedlings to facilitate the stabilisation of the soil. Nevertheless, the effective identification of potential climate challenges should represent a critical step for identifying suitable ecological management strategies and thereby avoiding potentially divergent and (or) unproductive rehabilitation outcomes - particularly during the highly dynamic and initial phases of early-ecosystem development.

\section{Appendix A}

\section{Spatial patterns of NDVI and extended description of remote sensing analyses}

NDVI values for two selected time periods and their associated coefficients of variation (CV-NDVI) were derived from the Global Inventory Modelling and Mapping Studies (GIMMS) dataset (Tucker et al., 2004). The GIMMS global dataset is derived from imagery acquired from the Advanced Very High Resolution Radiometer (AVHRR) instrument onboard the NOAA satellite series 7, 9, 11, 14, 16 and 17 (Tucker et al., 2004). It is available for a 25 year period from 

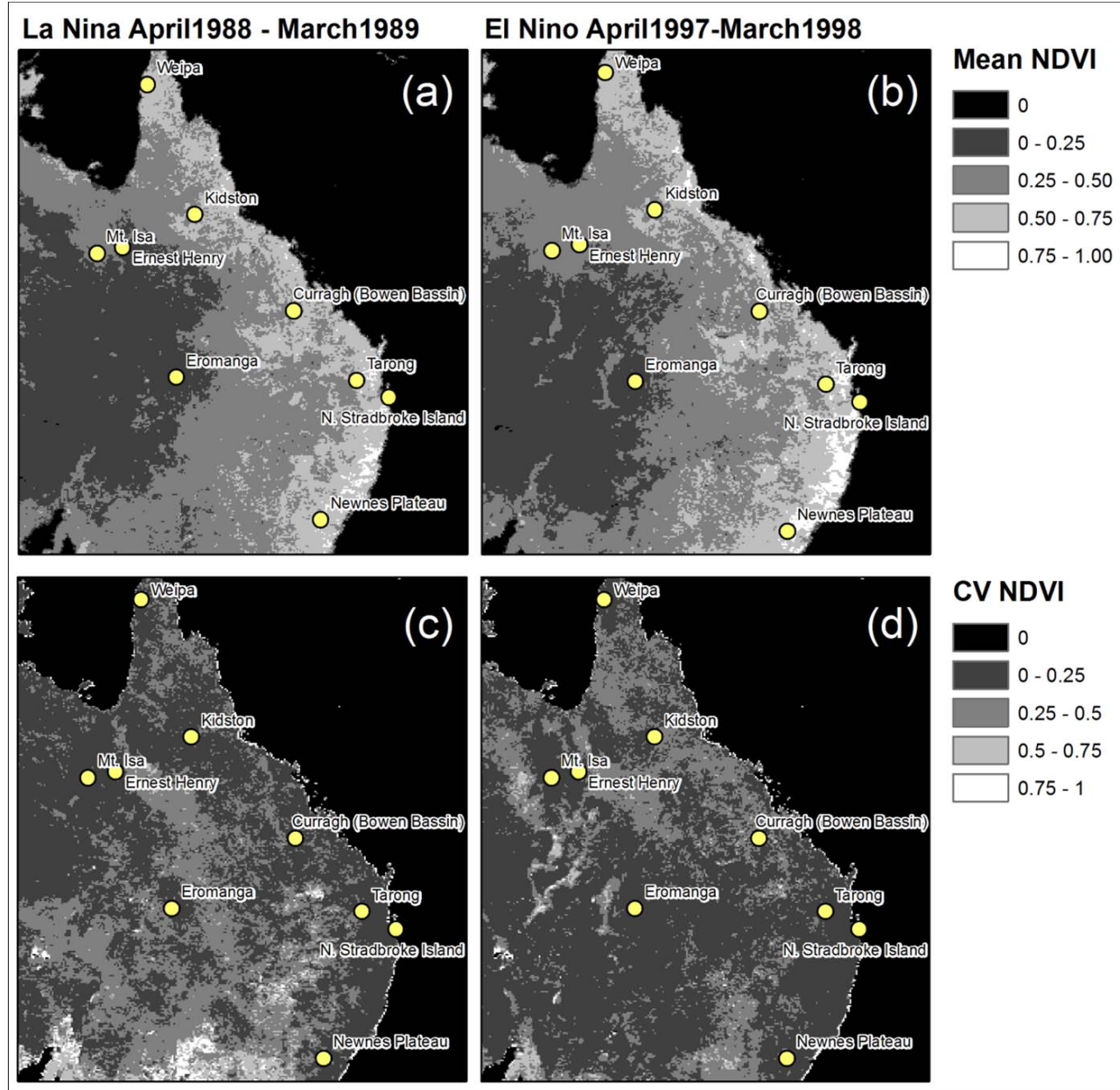

\section{NDVI}

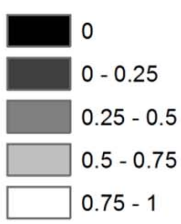

Fig. A1. Mean NDVI and coefficient of variation for the most extreme weather events across eastern Australia: (a and c) La Niña and (b and d) El Niño.

1981 to 2006 as bimonthly NDVI averages. The dataset has been radiometrically corrected for calibration, view geometry, volcanic aerosols, and other effects not related to vegetation change (Tucker et al., 2005). It is ideal for this study due to its continental extents with high temporal replication and sufficient historical data to observe trends in vegetation at decadal scales at which climate operate. Furthermore, the radiometric correction allows for the comparison of NDVI values at multiple locations found within different AVHRR scenes. The pixel size of the AVHRR GIMMs dataset was $7.4 \mathrm{~km}$, however, the spatial resolution is much larger because of smoothing that results from point density function of the sensor and the processing methods. The environmental conditions surrounding the mines will be a key driver of the pixel value as opposed to the mine itself. The impact of pixel size was qualitatively assessed through comparing surrounding pixel values to the pixel value for the mine. This assessment was important as the NDVI values were used to measure bioregional vegetation patterns not the condition of the vegetation on the mine.
Two one-year periods were chosen to represent extremes in climate found within Australia. Each time period is represented as an aggregate of 24 scenes within a one year period describing NDVI during an El Niño and La Niña Southern Oscillation period. El Niño/La Niña-Southern Oscillation, is a quasi-periodic climate pattern that occurs across the tropical Pacific Ocean approximately every five years. They cause extreme weather such as floods and droughts in many regions of the world. These two extreme weather years were used to represent NDVI within the study rather than averaging the NDVI values for the complete datasets (1981 to 2006) in which the start and end dates are arbitrary in relation to weather conditions.

The two events chosen represent the most recent of the 12 strongest El Niño and La Niña events identified in an analysis by Bureau of Meteorology (Bureau of Meteorology, 2012e, c) within the period where GIMMS data is available (Table A1). The El Niño begun in April 1997 and the La Niña period begun in April 1988 (Bureau of Meteorology, 2012b, a). For each of the periods a whole year of data was captured, 
as the El Niño/La Niña weather events lasted approximately the entire period. The La Niña event lasted from April 1988 to July 1989 and the El Niño event lasted for April 1997 to March 1998. This was to capture the annual trends in weather such as wet and dry season. It was important to capture a whole year of data as rainfall in temperate areas fall in winter months and tropical areas in the summer months. Thus, if we are truncating the dataset to a period of less than a year based on the length of the El Niño and La Niña events, we potentially could have biased the data to include rainfall periods only for the temperate or only for the tropical areas. The average and the coefficient of variation (mean / standard deviation) was calculated for the two time periods.

Acknowledgements. The authors wish to thank all three reviewers and the Guest-Editors for their careful insight leading to the final publication of this manuscript. The study was made possible by postdoctoral fellowship schemes and early-career research funding from the Centre for Mined Land Rehabilitation and The University of Queensland in support of PA, SA, and AL. Further financial support was awarded to PA from the Natural Sciences and Engineering Research Council (NSERC) of Canada.

Edited by: R. F. Hüttl

\section{References}

Audet, P., Gravina, A., Glenn, V., McKenna, P., Vickers, H., Gillespie, M., and Mulligan, D. R.: Structure of vegetation development on rehabilitated North Stradbroke Island: Above/belowground feedback may facilitate alternative ecological outcomes, Ecol. Process., 2, 20, doi:10.1186/2192-1709-220, 2013.

Bao, N., Lechner, A., Fletcher, A., Erskine, P., Mulligan, D., and Bai, Z.: Spoting long-term changes in vegetation over short-term variability, International Journal of Mining, Reclamation and Environment, doi:10.1080/17480930.2012.710505, 2012.

Bell, L. C.: Establishment of native ecosystems after mining Australian experience across diverse biogeographic zones, Ecol. Eng., 17, 179-186, doi:10.1016/S0925-8574(00)00157-9, 2001.

Bradshaw, A.: Restoration of mined lands-using natural processes, Ecol. Eng., 8, 255-269, doi:10.1016/s0925-8574(97)00022-0, 1997.

Bureau of Meteorology: Climate data, available at: http://www. bom.gov.au/climate/data/?ref=ftr, last access: 19 November 2012a.

Bureau of Meteorology: Australian rainfall patterns during El Niño events, Australian Government, available at: http://www.bom. gov.au/climate/enso/ninocomp.shtml, last access: 19 November 2012b.

Bureau of Meteorology: Australian rainfall patterns during La Niñ a events, Australian Government, available at: http://www.bom. gov.au/climate/enso/ninocomp.shtml, last access: 19 November 2012c.
Bureau of Meteorology: El Niño - Detailed Australian Analysis, Australian Government, available at: http://www.bom.gov. au/climate/enso/enlist/, last access: 19 November 2012d.

Bureau of Meteorology: La Niña - Detailed Australian Analysis, Australian Government, available at: http://www.bom.gov. au/climate/enso/enlist/, last access: 19 November 2012e.

Bureau of Meteorology: Australian Government: Design Rainfalls: http://www.bom.gov.au/water/designRainfalls/index.shtml, last access: 15 April, 2013, 2013.

Burton, M., Jasmine Zahedi, S., and White, B.: Public preferences for timeliness and quality of mine site rehabilitation. The case of bauxite mining in Western Australia, Resour. Polic., 37, 1-9, http://dx.doi.org/10.1016/j.resourpol.2012.01.004, 2012.

DEHP: Guideline Mining - Rehabilitation requirements for mining projects, Department of Environment and Heritage Protection, Queensland Government, available at: http://www.ehp.qld. gov.au/, 2012.

DERM: Protecting Queensland's strategic cropping land: A policy framework. Department of Environment and Resource Management, Queensland Government, available at: http://www.derm.qld.gov.au/land/planning/pdf/ strategic-cropping/strategic-cropping-policy-complete.pdf, 2010.

Doley, D., Audet, P., and Mulligan, D. R.: Examining the Australian context for post-mined land rehabilitation: reconciling a paradigm for the development of natural and novel ecosystems among post-disturbance landscapes, Agr. Ecosyst. Environ., 163, 85-93, doi:10.1016/j.agee.2012.04.022, 2012.

Doley, D. and Audet, P.: Adopting novel ecosystems as suitable rehabilitation alternatives for former mine sites, Ecol. Proc., 2, 22, doi:10.1186/2192-1709-2-22, 2013.

DRET, Department of Resources, Energy and Tourism: Mine Closure and Completion. Leading Practice Sustainable Development Program for the Mining Industry: http://www.ret.gov.au/resources/resources_programs/ lpsdpmining/handbooks/Pages/default.aspx, 2006.

Fraser, G. W., Day, K. A., Carter, J. O., and McKeon, G. M.: Rain on the rangelands: How intense is it?, Proceedings of the 16th Biennial Conference of the Australian Rangeland Society, Perth, 2010.

Gravina, A. and Grigg, A.: Mt. Isa mine rehabilitation monitoring 2004 assessment, The University of Queensland, Brisbane, 82 pp., 2004.

Gravina, A. and Grigg, A.: Monitoring and assessment of rehabilitation for the closure of Kidston Gold Mine 2007 Assessment, The University of Queensland, Brisbane, 82 pp., 2007.

Gravina, A., McKenna, P., and Glenn, V.: Evaluating the success of mineral sand mine rehabilitation on North Stradbroke Island, Queensland: Comparisons with reference Eucalypt communities, P. Roy. Soc. of Queensland, 419-436, 2011.

Gravina, A., Glenn, V., and Audet, P.: Tarong coal Meandu Mine and Kunioon test pit rehabilitation monitoring and compliance with EA criteria - 2011 Assessment, The University of Queensland, Brisbane, 98 pp., 2012.

Green, D. G. and Sadedin, S.: Interactions matter - complexity in landscapes and ecosystems, Ecol. Complex., 2, 117-130, doi:10.1016/j.ecocom.2004.11.006, 2005. 
Harris, J. A., Hobbs, R. J., Higgs, E., and Aronson, J.: Ecological restoration and global climate change, Restor. Ecol., 14, 170176, doi:10.1111/j.1526-100X.2006.00136.x, 2006.

Hinz, C., McGrath, G. S., and Hearman, A. J.: Towards a climate based risk assessment of land rehabilitation, Mine Closure 2006, Perth, 2006.

Hobbs, R. J., Higgs, E., and Harris, J. A.: Novel ecosystems: implications for conservation and restoration, Trends Ecol. Evol., 24, 599-605, doi:10.1016/j.tree.2009.05.012, 2009.

Hodgkinson, J. H., Littleboy, A., Howden, M., Moffat, K., and Loechel, B.: Climate adaptation in the Australian mining and exploration industries., 2010.

Hutchinson, M. F., McIntyre, S., Hobbs, R. J., Stein, J. L., Garnett, S., and Kinloch, J.: Integrating a global agro-climatic classification with bioregional boundaries in Australia, Global Ecol. Biogeo., 14, 197-212, doi:10.1111/j.1466-822x.2005.00154.x, 2005.

IBRA 7: Interim Biogeographic Regionalisation for Australia, Australian Government Department of Sustainability, Environment, Water, Population and Communities, 2012.

Jones, H. P., Hole, D. G., and Zavaleta, E. S.: Harnessing nature to help people adapt to climate change, Nature Clim. Change, 2, 504-509, doi:10.1038/NCLIMATE1463, 2012.

McKenna, P. and Baiquni, H.: Curragh coal mine rehabilitation monitoring 2010, The University of Queensland, Brisbane, 72 pp., 2011.

Myers, N., Mittermeier, R. A., Mittermeier, C. G., da Fonseca, G. A. B., and Kent, J.: Biodiversity hotspots for conservation priorities, Nature, 403, 853-858, http://www.nature.com/nature/ journal/v403/n6772/suppinfo/403853a0_S1.html, 2000.
Pessarakli, M.: Handbook of plant and crop physiology, Marcel Dekker, New York, 2001.

Pinzon, J. E., Brown, M. E., and Tucker, C. J.: Satellite time series correction of orbital drift artifacts using empirical mode decomposition, in: Hilbert-Huang Transform: Introduction and Applications, edited by: Huang, N. and Shen, S., World Scientific Publishing, Singapore, 167-186, 2005.

Tibbett, M., Mulligan, D., and Audet, P.: Recent advances in restoration ecology: examining the modern Australian agroecological and post-mining landscapes, Agr. Ecosyst. Environ., 163, 1-2, doi:10.1016/j.agee.2012.07.007, 2012.

Tucker, C. J., Pinzon, J. E., and Brown, M. E.: Global Inventory Modeling and Mapping Studies 2.0, http://glcf.umiacs.umd.edu/ data/gimms/index.shtml, University of Maryland, College Park, MD 2004.

Tucker, C. J., Pinzon, J. E., Brown, M. E., Slayback, D. A., Pak, E. W., Mahoney, R., Vermote, E. F., and El Saleous, N.: An extended AVHRR 8-km NDVI dataset compatible with MODIS and SPOT vegetation NDVI data, Int. J. Remote Sens., 26, 44854498, doi:10.1080/01431160500168686, 2005.

Vickers, H., Gillespie, M., and Gravina, A.: Assessing the development of rehabilitated grasslands on post-mined landforms in north west Queensland, Australia, Agr. Ecosyst. Environ., 163, 72-84, doi:10.1016/j.agee.2012.05.024, 2012.

Williams, J., Hook, R. A., and Hamblin, A.: Agro-ecological regions of australia - methodologies for their derivation and key issues in resource management, CSIRO Land and Water, 88 pp., 2002. 